\title{
A Clinical Study of the Effect of Low-Level Laser Treatment on the Clinical Stability of Immediately Loaded Implants in Posterior Maxilla
}

Alkinan Alashhab ${ }^{1}$, Isam Alkhoury ${ }^{2}$, Ghaith Sahtout ${ }^{3 *}$

${ }^{1} \mathrm{Ph}$.D. Student at Department of Oral and Maxillofacial Surgery, Faculty of Dental medicine, Damascus University, Syria. ${ }^{2}$ Professor at Department of Oral and Maxillofacial Surgery, Faculty of Dental medicine, Damascus University, Syria.

${ }^{3}$ Master Student at Department of Orthodontics, Faculty of Dental medicine, Damascus University, Syria.

\section{Abstract}

Background: Immediate loading of implants became a necessity in order to reduce the period of osseointegration. Photo biomodulation is a non-invasive treatment that bio-stimulates the new-formed bone on the cellular level in order to improve the quality of bone around implants.

Objectives:This study aimed to evaluate the efficacy of Low-Level Laser on clinical stability of the immediately loaded implants.

Materials \& Methods: 24 Megagen Implants were used in 12 patients in the split-mouth technique. $808 \mathrm{~nm} \mathrm{GaAlAs} \mathrm{Laser}$ with $4 \mathrm{~J}$ power per point was used for two weeks with an application every other day. The two implants in each patient were loaded immediately ( 1 week after implantation) by full acrylic crowns. Clinical stability was measured by Mega-ISQ and the measurements were held in the same operating day, one week after implantation and 3 months after implantation. For statistical analysis, T-test for independent groups and T-test for paired group were used to determine the differences between the two groups.

Results: No signifiable differences in ISQ values were noticed between the two groups in the operating day and 3 months after. While there were signifiable differences one week after implantation.

Conclusions: Within the limitations of this study, using LLLt can improve the bone quality around implants but with no signifiable differences.

Keywords: Immediate Loading; ISQ; LLLT; Clinical Stability of Implants.

\section{Introduction}

Dental implants have high success rates in rehabilitating edentulous patients if certain conditions are taken into consideration during treatment. Nevertheless, the prognosis of the implants remain difficult to predict. Osseointegration depends on several factors such as the appropriate patient, biologically receptive materials, the surgical experience of the doctor, and the appropriate recovery duration [1]. The primary stability depends on the mesenchymal contact between the bone tissue and the implant surface immediately after implantation. Secondary stability comes through the formation of new living bone tissue that fills the space between the existing alveolar bone and the implant surface instead of the dead bone [2]. The healing period for implants varies according to the recommendations of 3-4 months. This duration increases in the maxillary and the posterior region of the mandibular due to the increase of spongy bone and it can reach 5-6 months.

In the implants placed in the D4 bone of density, we must add 1-2 months to the previous period, which makes a long duration of functional loading over the implants [3]. The immediate loading technique was used in the context of rehabilitating the mouth using dental implants in order to reduce the treatment duration, as this technique eliminates the time needed to wait for the recovery duration and allows the use of temporary compensation immediately after implant insertion and keeps the implants in a functional state during the healing period. However, some problems asso-

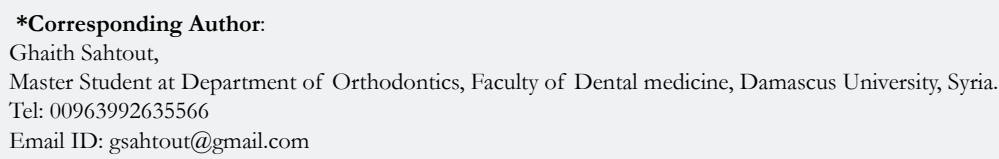

Copyright: Ghaith Sahtout ${ }^{\circ} 2021$. This is an open-access article distributed under the terms of the Creative Commons Attribution License, which permits unrestricted use, distribution and reproduction in any medium, provided the original author and source are credited. 
ciated with this technology emerged, including the low survival rate of implants compared to those traditionally loaded immediately [4]. The implant stability is measured based on a variety of mechanical, histological, clinical, and chemical methods where resonant frequency analysis is considered Resonance Frequency Analysis (RFA) is the non-aggressive clinical method to measure implant stability performed using Ostell device it gives values measured by ISQ (Implant Stability Quotient) and it has been used in many clinical studies. The technique of resonant frequency analysis is the correlation test of a bone-implant system in which very small forces are applied by the induction of a transducer. These forces are applied laterally to the implant and the amount of movement of the implant is measured. Which practically simulates the conditions of the occlusion loading of this implant. This method thus allows giving information about the state of the implant at any time during the process [5]. Laser therapy is recently introduced as a non-invasive technique that uses low-power lasers to improve bone healing. Soft lasers are known in general medicine for their ability to improve wound healing, collagen synthesis, and cell multiplication of fibroblasts.Most of the studies focused on evaluating the bioactivity of these lasers on the multiplication of osteoclasts, collagen placement, and increased bone morphology compared with tissues that aren't exposed to the laser [6]. There are no adequate studies in the medical literature evaluating the effect of low-power lasers on osseointegrationaround dental implants, although there are many studies that have suggested a clinically positive effect of low-powerlaser on implant stability [3], considering that the bone is of low-density type D3-D4 located in the upper molar region, it is the bone with the lowest success rate of dental implant treatment due to the initial lack of stability, so laser can have a beneficial effect on implant treatment in that area [7].

\section{Objectives:}

Evaluating the efficacy of low-power laser biostimulation on Osseointegration around implants in the posterior region of the maxillary and made for immediate loading.

\section{Materials and Methods}

The study belongs to experimental studies (a comparison study between a study group and a control group), the split-mouth design is applied so that the patient himself was a control sample on one side and a study sample on the other side.

\section{The study sample}

Patients attending the dental implant unit and outpatient clinic of the department of oral and maxillofacial surgery at the Faculty of Dentistry at Damascus University, who suffer from symmetric loss confined to the posterior maxillary teeth and meet the following inclusion criteria:Adults over 18 years old, posterior symmetric teeth loss in the maxillary, sufficient bone quantity to receive the dental implant without the need for any advanced surgical procedures, absence of any tooth extraction history during the past six months.

\section{Sample size calculation}

The sample size was calculated using the G- power 3.1.9.2 pro- gram based on the data of Torkzaban study 2018 [3], where the measured ISQ were enteredwitha resonant frequency analyzer device electronically Osstell that measures the initial stability of the implant. The result was that a sample size of 24 implants were applied in 12 patients.

\section{Surgical work}

The surgery was performed in the implantation unit at Damascus University College and dentistry and using the Korean Megagen implant system. Implants with a united diameter and length (4 $\mathrm{mm} \times 10 \mathrm{~mm}$ ) were introduced to all patients and at both sides, according to the following order:

After preparing the surgical field and requesting the patient to rinse with chlorhexidine solution for 30 seconds, local anesthesia was performed with filtration from the vestibular and palatine sides on both ends.

A flap was not raised in this research, but rather a non-flap implant method was used where starting with the positioning bur in the implant kit where the implant motor was set at a speed of 800 rpm and a torque of $35 \mathrm{~N}$. We enter after ascertaining the axis of the bur in both the buccal-lingual and medial-lateral directions (Figure 1).

The special burs were followed until reaching the last bur for inserting an implant with a diameter of $4 \mathrm{~mm}$, and this bur in the system used in the research has a diameter of $3.6 \mathrm{~mm}$, and we should take care to enter all burs to the full predetermined length, making sure of the adequacy of irrigation with the syringe and saline solution, and there is no need to use a counter or any other bur.

Implants with a diameter of $4 \mathrm{~mm}$ and a length of $10 \mathrm{~mm}$ were inserted at the sides, using the surgical handpiece of the implant's motor, after it was set to the insertion speed of 50 revolutions/ minute and the insertion torque of 35 Newton without using saline irrigation (Figure 2). The implant was visually confirmed to reach the level of the apex of the alveolar bone under the periodontal soft tissue.

Initial implant stability was measured using Megastell from the vestibular-palatine and medial-lateral aspects.

Install the transfer and prepare the patient in order to begin the prosthetic procedure.

\section{The compensatory stage}

Work in the compensatory phase began immediately after the surgical work, in the following order:

The transfer impression was installed at both sides, using a closedtray technique (figure 3).

Condensation silicone, both hard and soft, was used for taking the imprint, the imprint was taken with a single-stage technique where the light silicone was injected around the imprint conveyor and then the tray was filled with the putty silicone.

The imprint was removed from the patient's mouth and then 
installed with the special laboratory Analogue implant and was re-inserted into the imprint according to the perforations on the conveyor. (figure 4)

Gingival formers were placed on the implants, ensuring the appropriate size and length for the gingival formers.

Making temporary prostheses using the indirect technique where imprints are taken and sent to the professional technician to make temporary acrylic prostheses on the temporary supports of the Megagen implant system.

The temporary compensation was fabricated on the seventh day of the surgical operation and it was ensured that there were no occlusal contacts with occlusion papers (Figure 6). The strut screw was tightened with a ratchet wrench of the implant system at a torque of $35 \mathrm{~N}$ and the position of the strut screw was closed by flowable composite.

\section{Laser application}

The laser application phase took place in the laser unit at the Faculty of Dentistry, University of Damascus, and the laser device used in this research was the Klas DX device - GaAlAs from the Taiwanese Konftec company (Fig.7), and the following parameters were adopted:

Capacity of 250 mill watts, wave length $808 \mathrm{~nm}$, application time 16 seconds, total energy of 4 joules in each of the vestibular and lingual sides.

The laser was used in contact with the tissue after drying and in the mode of continuous pulse.Use a $0.07 \mathrm{~cm}$ crooked head.

In the studied part which determined randomly in each patient, the gingival tissue was dried, the laser device was set to the previous barometer, and the device's head were placed in contact with the tissue from the vestibular side in the middle of the distance between the top of the implant and its apex.

After finishing the vestibular side, we move to the palatine side, where the work is done in the same way. The mucous is dried and the head is applied in a contact in the middle of the approximate length of the implant.

The laser was applied in the first two weeks postoperatively, with 48-hour intervals between each application session. (Figure 8)

As for the control sample, the laser was not applied, and the rest of the procedures were followed, as in the study sample.

\section{Measurement of clinical stability of implants}

The clinical stability of the implants was measured using Mega ISQ device from Megagen and that in:

The same day of the surgical procedure (immediately after implant insertion).

One week after performing the surgical procedure before installing the temporary compensation.

After 3 months of the implant procedure, when the temporary compensation is replaced with the final compensation.

The three measurement times were made in the following order: The gingival former was removed (at the time of the second measurement) and the temporary prosthesis with its abutment (at the time of the third measurement).

Special posts from the Smart Pegs implant company were manually installed on the implants and were tightened manually until there were no movement in them (Figure 9).

The Mega ISQ is characterized by its measurement of implant stability in the vestibular-lingual and medial-lateral directions and averaging the two measures.

The device head is approximated to the post installed on the implant without direct contact in one direction until it gives a value for ISQ and then we adjust the position of the device's head in the other direction without contact as well. (Figure 10). The average value given by the device had been taken and recorded in the patient data. The work is repeated on the second side in the same way.

Figure 1. The first bur used to prepare the implant's socket.

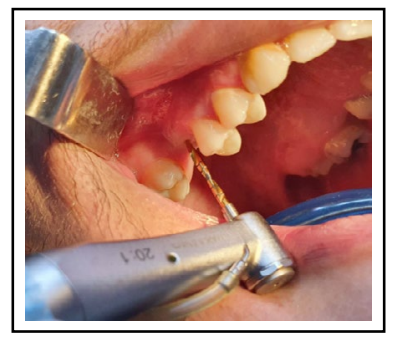

Figure 2. Inserting the implant in its place (35 newtons $-50 \mathrm{rpm})$.

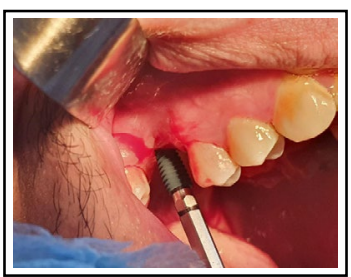


Figure 3. Transfers in their places before taking the impression.

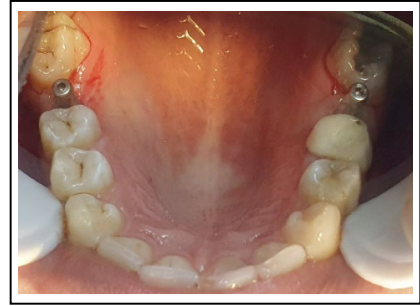

Figure 4. The final impression with transfers.

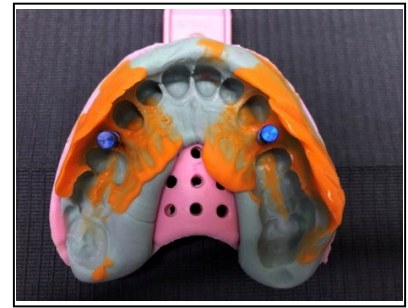

Figure 5. Gingival formers in their places.

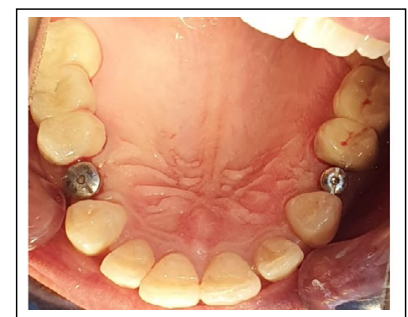

Figure 6. Acrylic prosthesis.

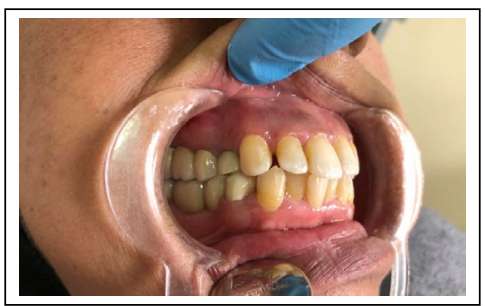

Figure 7. Laser device and laser safety eyewear.

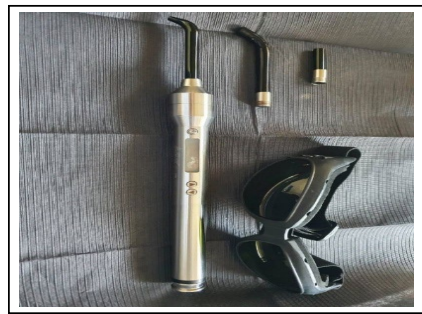

Figure 8. Laser application in both buccal and lingual sides in 10th day.

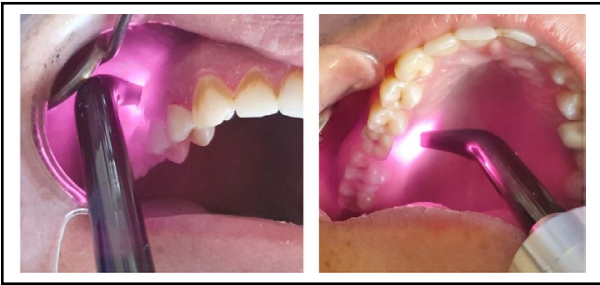

\section{Results}

Table (1) shows the descriptive statistics of the clinical stability values of ISQ implants where:

ISQ 0: The ISQ value measured on the same day of surgery, ISQ 1: The ISQ value measured after one week of surgery, ISQ 2: The ISQ value measured after 3 months of surgery.
And when performing the Shapieo -Wilk test to determine the pattern of data distribution, the distribution was found to be normal $(\mathrm{P}>0.05)$ Thus, the value of the parameter tests was chosen.

T-Test was performed for independent samples in order to compare the two study group and the control group at the three times the measurement was performed (Table 2). 
A t-test was performed for correlated samples in the control group to compare the ISQ values between each of the two study times, and statistically significant differences were observed when comparing each study time table (3).

A t-test was performed for the paired samples in the study group to compare the ISQ values between each of the two study times, and statistically significant differences were observed when comparing each study time Table (4).

\section{Discussion}

Several clinical and experimental studies have shown promising results regarding the ability of low-power lasers to improve bone healing, but they have provided little information on the effect of these lasers on the bone fusion of dental implants.

GaAlAs laser with a wavelength of $808 \mathrm{~nm}$ was chosen due to its effective effects on both fibroblasts and osteoblasts that have been proven by several authors in various clinical and laboratory studies $[8,9]$.

Figure 9. Smart pegs in their places.

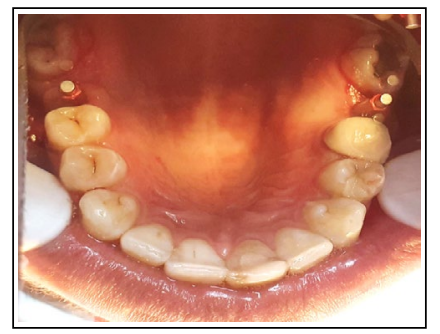

Figure 10. the application of Mega ISQ device in buccal and lingual sides.

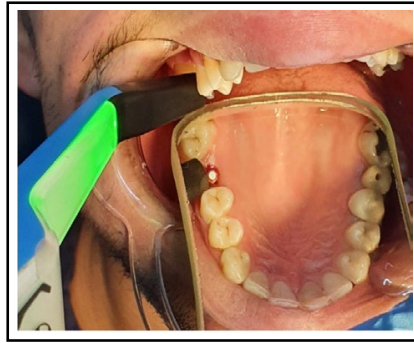

Table 1. Shows the descriptive statistics for ISQ values.

\begin{tabular}{|c|c|c|c|c|c|c|}
\hline $\begin{array}{c}\text { Studied } \\
\text { variable }\end{array}$ & $\begin{array}{c}\text { Studied } \\
\text { group }\end{array}$ & Mean & Median & $\begin{array}{c}\text { Minimum } \\
\text { limit }\end{array}$ & $\begin{array}{c}\text { Maximum } \\
\text { limit }\end{array}$ & $\begin{array}{c}\text { Standard } \\
\text { deviation }\end{array}$ \\
\hline \multirow{2}{*}{ ISQ 0 } & Study & 75 & 74 & 72.35 & 77.641 & 4.156 \\
\cline { 2 - 7 } & Control & 75.25 & 74.5 & 73.098 & 77.403 & 3.388 \\
\hline \multirow{2}{*}{ ISQ 1 } & Study & 76.5 & 76 & 74.225 & 78.775 & 3.580 \\
\cline { 2 - 7 } & Control & 73.83 & 74 & 72.281 & 75.386 & 2.443 \\
\hline \multirow{2}{*}{ ISQ 2 } & Study & 70.83 & 70.5 & 67.905 & 73.762 & 4.609 \\
\cline { 2 - 7 } & Control & 68.16 & 68.5 & 65.068 & 71.266 & 4.877 \\
\hline
\end{tabular}

Table 2. Shows that there were no statistically significant differences between the two groups in the first time (the same day of surgery) and the third time ( 3 months after the transplant procedure), while there were statistically significant differences $(\mathbf{P}<0.05)$ in the second time (a week after implant).

\begin{tabular}{|c|c|c|c|c|}
\hline \multicolumn{5}{|c|}{ T- test results for independent samples } \\
\hline \multirow{2}{*}{} & & \multicolumn{2}{|c|}{ T-test for differences between means } \\
\cline { 3 - 5 } \multicolumn{2}{|c|}{} & Calculated t-test & p-value & significant difference \\
\hline \multirow{2}{*}{ ISQ 0 } & Equal variances are assumed & -0.162 & 0.873 & \multirow{2}{*}{$*$} \\
\cline { 2 - 4 } & Equal variances are not assumed & -0.162 & 0.873 & \multirow{2}{*}{$*$} \\
\hline \multirow{2}{*}{ ISQ 1 } & Equal variances are assumed & 2.131 & 0.044 & \multirow{2}{*}{-} \\
\cline { 2 - 5 } & Equal variances are not assumed & 2.131 & 0.46 & \\
\hline \multirow{2}{*}{ ISQ 2 } & Equal variances are assumed & 1.377 & 0.182 & \\
\cline { 2 - 5 } & Equal variances are not assumed & 1.377 & 0.183 & \\
\hline
\end{tabular}

* Significant difference

- No significant difference 
Table 3.

\begin{tabular}{|c|c|c|c|c|}
\hline \multicolumn{4}{|c|}{ A t-test for correlated samples in the control group } \\
\hline & $\begin{array}{c}\text { Calculated } \\
\text { t-test }\end{array}$ & $\begin{array}{c}\text { Freedom } \\
\text { degree }\end{array}$ & p-value & $\begin{array}{c}\text { significant } \\
\text { difference }\end{array}$ \\
\hline $\begin{array}{c}\text { ISQ0- } \\
\text { ISQ1 }\end{array}$ & 2.327 & 11 & 0.040 & $*$ \\
\hline $\begin{array}{c}\text { ISQ0- } \\
\text { ISQ2 }\end{array}$ & 8.183 & 11 & 0.000 & $*$ \\
\hline $\begin{array}{c}\text { ISQ1- } \\
\text { ISQ2 }\end{array}$ & 4.844 & 11 & 0.001 & $*$ \\
\hline
\end{tabular}

* Significant difference

Table 4.

\begin{tabular}{|c|c|c|c|c|}
\hline \multicolumn{7}{|c|}{ A t-test for correlated samples in the study group } \\
\hline & Calculated t-test & Freedom degree & p-value & $\begin{array}{c}\text { significant } \\
\text { differences }\end{array}$ \\
\hline ISQ0-ISQ1 & -2.462 & 11 & 0.032 & $*$ \\
\hline ISQ0-ISQ2 & 4.844 & 11 & 0.001 & $*$ \\
\hline ISQ1-ISQ2 & 6.304 & 11 & 0 & $*$ \\
\hline
\end{tabular}

Lasers in the infrared spectrum have a higher penetration depth of tissue compared to lasers in the red or blue spectrum in visible light [10], so bone scanners can absorb laser energy better due to little water absorption at this wavelength [11].

Khadra has shown that there is no standardized protocol for the use of lasers for the treatment of dental implants. We have several options regarding wavelength and laser power when used to improve bone healing [6].

The Resonnance Frequency Analysis technique was presented by [12] as a non-aggressive technique for measuring the clinical stability of implants. This technique is based on the application of torsion forces that simulate the clinical load on the implants and its different directions and provides information about the stiffness of the connection between the bone and the implant, given that the torsional forces are the most types of stress that are subjected to dental implants [13].

This technique has been widely used in recent years in order to measure the initial stability and thus determine the period of time required for Osseo integration before loading the implant, contributing to confirm whether sufficient stability has been obtained in the second surgical phase and thus determining implants with a high risk of failure $[14,15]$.

ISQ values gradually decreased in the control group between time 0 (75.25) and time 1 (73.83), then it decreased accordingly after 3 months (68.16), where there were statistically significant differences in the three times, but in the study group, the ISQ value increased between time 0 (75) and time 1 (76.5), and then decreased in time 2 (70.83).

The increase in the value of ISQ in the first week can be explained by the increase in cell differentiation multiplication and the pro- duction of organic bone matrix around the implants, and that the power of the laser bio stimulation depends on the physiological state of the cell at the time of irradiation and on the effectiveness of the laser during the initial stage of cell proliferation and the initial differentiation of undifferentiated cells [16].

As for the decrease in the value of ISQ at the third time, it can be explained that the cells received the laser energy in the initial stages of the bone restoration and repair process, which accelerated their differentiation and metabolism during the irradiation period, and since the application of the laser stopped after 14 days, it can be assumed that the metabolism process is a process. Related to the energy dose received.

According to Pinheiro, cellular elements in the early stages of bone healing are more likely to be affected by laser treatment, and repeated application of the laser is effective when applied in the cellular stage of bone healing when the number of bone mares is greater. In later stages, the large number of cells leads to a greater placement of the bone-like substance that will precipitate out hydroxyapatite, leading to the maturation of new bone [16].

Scientist Zhou studied the factors that can affect RFA. These factors include jaw type (mandibular or maxillary), bone quality (D1 -4), patient gender (male or female), implant length and diameter. Through his study, he revealed that the quality of the bone receiving the implant is the main factor affecting the ISQ, in contrast to the hypothesis whichsays that the length and diameter of the implant took the primary credit for the high value of the clinical stability of the implants [17].

In our study the bone quality was D2-D3 in all patients, and there were no differences between the radial bone densities in the two groups at the time of implantation. This is the probable reason for the lack of statistical differences between the ISQ values at different times of measurement. 
In the two-way comparison between the two groups, there were no significant differences between the two groups at the time of surgery or in the second time after 3 months, while these differences were found in the first time after a week, meaning that the low-energy laser showed the greatest effect in the first week after surgeryand had no effect after 3 months.

The absence of statistically significant differences between the two groups can be explained by a number of hypotheses, including that although the laser was applied in one side only without the other side in the same patient (bisected mouth technique), it is not certain that the inflammatory effect of the laser is a general effect. Or is it possible to isolate the induction in the application area on the osteoblasts, as it has been suggested that low-power lasers lead to systemic effects in areas far from the place of application [18], It is also possible that the laser effect was hidden by the high initial stability of the implants in both groups in addition to the geometry of the implant. In our study the lowest value of ISQ was 72.35, which is a large enough value for immediate loading of implants. For this reason, it is possible that the laser effect was not the main effective factor in the stability of the implant as it is one of the influencing factors (initial stability during implantation - the quality of the bone receiving the implant). Thus, studies similar to ours - in different conditions of bone quality (diabetes - osteoporosis - low ISQ values) can further clarify the potential effect of laser on bone fusion.

The results of our study differed with that of Morales Garcia, who used GaAlAs laser with a wavelength of $830 \mathrm{~nm}$ and did not find it to have a statistically significant effect. Our study also disagreed with Mandi who used a $637 \mathrm{~nm}$ laser and didn't notice the absent effect in improving the ISQ value at all times [7, 19].

The researchers in the two previous studies agreed that the laser had increased the number of osteogenic cells in the initial stage of healing, but that this had no effect on the clinical stability.

The results of our study agreed with the Torkzaban study, for which the ISQ value gradually decreased in both groups and was the largest decrease after 10 days of implantation, whereas the ISQ value increased in our study the first week [3].

The results of our study agreed with the results obtained by Tatli, where he studied the changes in the ISQ value about the immediately loaded implants and found an increase in the ISQ value in the first month (in our study, the tip was in the first week), then it gradually began to decrease later, and this can be explained by the transformations that occur on the organic template around the implants after the first month when the reticular bone (lamellar) begins to turn into dense cortical bone [20].

\section{Conclusions}

The effectiveness of the low-power laser in increasing the clinical stability of implants in the posterior region of the mandibular in the first week after surgery, while it had no effect on the clinical stability after 3 months of implantation.

\section{References}

[1]. Albrektsson T, Brånemark PI, Hansson HA, Lindström J. Osseointegrated titanium implants. Requirements for ensuring a long-lasting, direct boneto-implant anchorage in man. Acta Orthop Scand. 1981;52(2):155-70.Pubmed PMID: 7246093.

[2]. Tirachaimongkol C, Pothacharoen P, Reichart PA, Khongkhunthian P. Relation between the stability of dental implants and two biological markers during the healing period: a prospective clinical study. Int J Implant Dent. 2016 Dec;2(1):27.Pubmed PMID: 27933572.

[3]. Torkzaban P, Kasraei S, Torabi S, Farhadian M. Low-level laser therapy with $940 \mathrm{~nm}$ diode laser on stability of dental implants: a randomized controlled clinical trial. Lasers Med Sci. 2018 Feb;33(2):287-93.

[4]. Gao J, Matsushita Y, Esaki D, Matsuzaki T, Koyano K. Comparative stress analysis of delayed and immediate loading of a single implant in an edentulous maxilla model. J Dent Biomech. 2014 May 14;5:1758736014533982. Pubmed PMID: 25342982.

[5]. Sennerby L. Resonance frequency analysis for implant stability measurements. A review. Integration Diagn Update. 2015;1:1-11.

[6]. Khadra M, Rønold HJ, Lyngstadaas SP, Ellingsen JE, Haanaes HR. Lowlevel laser therapy stimulates bone-implant interaction: an experimental study in rabbits. Clin Oral Implants Res. 2004 Jun;15(3):325-32.Pubmed PMID: 15142095.

[7]. Mandić B, Lazić Z, Marković A, Mandić B, Mandić M, Djinić A, et al. Influence of postoperative low-level laser therapy on the osseointegration of self-tapping implants in the posterior maxilla: a 6-week split-mouth clinical study. Vojnosanit Pregl. 2015 Mar;72(3):233-40.Pubmed PMID: 25958474.

[8]. Lopes CB, Pinheiro AL, Sathaiah S, Da Silva NS, Salgado MA. Infrared laser photobiomodulation (lambda $830 \mathrm{~nm}$ ) on bone tissue around dental implants: a Raman spectroscopy and scanning electronic microscopy study in rabbits. Photomed Laser Surg. 2007 Apr;25(2):96-101.Pubmed PMID: 17508844.

[9]. Bouvet-Gerbettaz S, Merigo E, Rocca JP, Carle GF, Rochet N. Effects of low-level laser therapy on proliferation and differentiation of murine bone marrow cells into osteoblasts and osteoclasts. Lasers Surg Med. 2009 Apr;41(4):291-7.

[10]. Welch AJ, Torres JH, Cheong WF. Laser physics and laser-tissue interaction. Texas Hear Inst J. 1989;16(3):141-9.

[11]. Blaya D, Guimarães M, Pozza D, Weber J, de Oliveira MG. Histologic study of the effect of laser therapy on bone repair. J Contemp Dent Pract.2008; $9(6): 41-8$.

[12]. Meredith N, Alleyne D, Cawley P. Quantitative determination of the stability of the implant-tissue interface using resonance frequency analysis. Clin Oral Implants Res. 1996 Sep;7(3):261-7.

[13]. Sennerby L, Meredith N. Implant stability measurements using resonance frequency analysis: biological and biomechanical aspects and clinical implications. Periodontol 2000. 2008;47:51-66.Pubmed PMID: 18412573.

[14]. Karl M, Graef F, Heckmann S, Krafft T. Parameters of resonance frequency measurement values: a retrospective study of 385 ITI dental implants. Clin Oral Implants Res. 2008 Feb;19(2):214-8.Pubmed PMID: 18067599.

[15]. Aparicio C, Lang NP, Rangert B. Validity and clinical significance of biomechanical testing of implant/bone interface. Clin Oral Implants Res. 2006 Oct;17 Suppl 2:2-7.Pubmed PMID: 16968377.

[16]. Pinheiro AL, Gerbi ME. Photoengineering of bone repair processes. Photomed Laser Surg. 2006 Apr;24(2):169-78.Pubmed PMID: 16706695.

[17]. Zhou W, Han C, Yunming L, Li D, Song Y, Zhao Y. Is the osseointegration of immediately and delayed loaded implants the same?--comparison of the implant stability during a 3-month healing period in a prospective study. Clin Oral Implants Res. 2009 Dec;20(12):1360-6.Pubmed PMID: 19793319.

[18]. Rodrigo SM, Cunha A, Pozza DH, Blaya DS, Moraes JF, Weber JB, et al. Analysis of the systemic effect of red and infrared laser therapy on wound repair. Photomed Laser Surg. 2009 Dec;27(6):929-35.Pubmed PMID: 19708798.

[19]. García-Morales JM, Tortamano-Neto P, Todescan FF, de Andrade JC Jr, Marotti J, Zezell DM. Stability of dental implants after irradiation with an 830-nm low-level laser: a double-blind randomized clinical study. Lasers Med Sci. 2012 Jul;27(4):703-11.Pubmed PMID: 21732113.

[20]. Tatli U, Salimov F, Kürkcü M, Akoğlan M, Kurtoğlu C. Does cone beam computed tomography-derived bone density give predictable data about stability changes of immediately loaded implants?: A 1-year resonance frequency follow-up study. J Craniofac Surg. 2014 May;25(3):e293-9.Pubmed PMID: 24799099. 